\begin{tabular}{lcl}
\hline Bentham OPEN & The Open Neurology Journal & $\begin{array}{c}\text { The Open } \\
\text { Neurology } \\
\text { lournal } \\
\text { CrossMark }\end{array}$ \\
\hline
\end{tabular}

RESEARCH ARTICLE

\title{
Oxidative Stress Induces Senescence in Cultured RPE Cells
}

\author{
Nona Aryan, Brandi S. Betts-Obregon, George Perry and Andrew T. Tsin \\ Department of Biology, The University of Texas at San Antonio, San Antonio, TX, 78249, USA
}

\begin{abstract}
The aim of this research is to determine whether oxidative stress induces cellular senescence in human retinal pigment epithelial cells. Cultured ARPE19 cells were subjected to different concentrations of hydrogen peroxide to induce oxidative stress. Cells were seeded into 24 -well plates with hydrogen peroxide added to cell medium and incubated at $37^{\circ} \mathrm{C}+5 \% \mathrm{CO}_{2}$ for a 90 -minute period [at 0, 300, 400 and 800 micromolar (MCM) hydrogen peroxide]. The number of viable ARPE19 cells were recorded using the Trypan Blue Dye Exclusion Method and cell senescence was measured by positive staining for senescence-associated betagalactosidase (SA-beta-Gal) protein. Without hydrogen peroxide treatment, the number of viable ARPE19 cells increased significantly from 50,000 cells/well to 197,000 within 72 hours. Treatment with hydrogen peroxide reduced this level of cell proliferation significantly (to 52,167 cells at $400 \mathrm{MCM}$; to 49,263 cells at $800 \mathrm{MCM}$ ). Meanwhile, cells with a high level of positive senescence-indicator SA-Beta-Gal-positive staining was induced by hydrogen peroxide treatment (from a baseline level of $12 \%$ to $80 \%$ at $400 \mathrm{MCM}$ and at $800 \mathrm{MCM}$ ). Our data suggests that oxidative stress from hydrogen peroxide treatment inhibited ARPE19 cell proliferation and induced cellular senescence.
\end{abstract}

Keywords: ARPE-19 cells, Cellular senescence, Oxidative stress, SA-beta-Gal.

\section{INTRODUCTION}

Age-related macular degeneration (AMD), the leading cause of worldwide blindness in the elderly, is a bilateral ocular condition that affects the central area of retina known as the macula. The macula accounts for the majority of photopic (daytime, color) vision in humans. Thus, lesions developing in the macula have a major impact on human vision.

Histopathology features of AMD include focal drusen deposits and a loss of both photoreceptors and retinal pigment epithelial (RPE) cells leading to regional or global retinal atrophy [1].

Clinically, AMD is categorized into the dry (or atrophic) and the wet (or neovascular) forms. The most severe AMD vision loss is associated with patients exhibiting wet AMD while the dry form accounts for $20 \%$ of legal blindness in those that suffer from AMD [2].

Studies have suggested that oxidative stress to RPE cells and photoreceptors may contribute to the pathogenesis of age-related macular degeneration [3]. Oxidative stress occurs when reactive oxygen species (ROS) interact with macromolecules which modify their functions. Furthermore, AMD is an age-associated disease which makes aging a risk factor [4]. Although the vision loss of AMD is due to the loss of photoreceptors in the central retina, the initial pathogenesis of the disease involves degeneration of RPE cells [5]. Studies have suggested that RPE cells undergo an accelerated aging process [6] and since the loss of RPE cells is the critical event leading to irreversible vision loss, our aim is to examine oxidative damage to human retinal pigment epithelial cells in a cell line (ARPE19) with senescencerelated changes [7]. Our experimental results show that oxidative stress by hydrogen peroxide treatment led to enhanced cell senescence in vitro.

\footnotetext{
* Address correspondence to this author at the Department of Biology, The University of Texas at San Antonio, One UTSA Circle, San Antonio, Texas 78249, USA; Tel: +210-458-5480, Fax:+210-458-4472; E-mail: Andrew.Tsin@utsa.edu
} 


\section{MATERIALS AND METHODS}

\subsection{In Vitro Model}

ARPE19 cells were purchased from American Type Culture Collection (ATCC; Manassas, VA, USA). At passage 11 , cells were seeded in a $\mathrm{T} 75$ flask and cultured until confluent at $37^{\circ} \mathrm{C}$ with $5 \% \mathrm{CO}_{2}$. Cells were grown in Dulbecco's Modified Eagle's medium and supplemented with 10\% Fetal Bovine Serum (FBS) from Life Technologies Co. (Carlsbad, CA, USA).

\subsection{Hydrogen Peroxide Treatment}

Cells were trypsinized using Trypsin + EDTA and seeded into 24 well plates at 50,000 cells per well, $1 \mathrm{ml}$ DMEM $+10 \%$ FBS. After 24 hours of incubation at $37^{\circ} \mathrm{C}+5 \% \mathrm{CO}_{2}$, the growth medium was removed and replaced with serum-free medium (SFM). 24 hours later, the medium of selected wells were changed to SFM +300 micromolar (or $\mathrm{MCM}$ ) hydrogen peroxide, SFM $+400 \mathrm{MCM}$ or SFM $+800 \mathrm{MCM}$. After 90 minutes of hydrogen peroxide treatment, the medium in selected wells were changed to $1 \mathrm{ml}$ of DMEM $+10 \%$ FBS for the subsequent study on cell proliferation and senescence.

\subsection{Hydrogen Peroxide Treatment on Cell Proliferations}

To investigate cell proliferation after hydrogen peroxide treatments, cells with and without hydrogen peroxide treatments were incubated for 72 hours and then trypsinized (trypsin + EDTA) and harvested for counting using the Trypan Blue Dye Exclusion Method.

\subsection{Hydrogen Peroxide Treatment on Cell Senescence}

To investigate the effect of oxidative stress (induced by hydrogen peroxide) on retinal pigment epithelial cell senescence, ARPE19 cells were stained for S-Beta Galactosidase 24 hours after treatment with hydrogen peroxide. The Senescence Associated Beta-Galactosidase Staining Kit (Category No. K320-250; BioVision Incorporated, Milpitas, CA, USA) was used according to manufacturer's instructions. Stained cells were observed under an inverted microscope for the development of blue color.

\section{RESULTS}

\subsection{Hydrogen Peroxide Treatment Significantly Reduced Cell Proliferation}

ARPE19 cells with and without hydrogen peroxide treatment were seeded at 50,000 cells per well. After 72 hours of incubation, the number of viable cells in control wells (with 0 MCM hydrogen peroxide treatment) increased to 197,000 cells. On the other hand, the number of viable cells in wells containing hydrogen peroxide treatment exhibited a significantly lower level of cell proliferation. The number of ARPE19 cells with 300 MCM hydrogen peroxide treatment increased from 50,000 to 89,100 viable cells and those treated with 400 and 800 MCM hydrogen peroxide changed from 50,000 to 52,300 and to 48,900 cells respectively. Fig. (1) illustrates the changes in viable ARPE19 cell number corresponding to the three hydrogen peroxide treatment concentrations.

\subsection{Oxidative Stress (from Hydrogen Peroxide Treatment) Induced ARPE19 Cell Senescence}

Cells without (0 MCM) and with (300 MCM, $400 \mathrm{MCM}$ and $800 \mathrm{MCM}$ ) hydrogen peroxide treatments were incubated for 24 hours and stained for Senescence Associated Beta Galactosidase to study the level of cell senescence. Our results show that control (without hydrogen peroxide treatment) exhibited minimal blue stain for Beta Galactosidase (Fig. 2A) whereas treatment with $300 \mathrm{MCM}$ hydrogen peroxide resulted in an increase in percent of cells exhibiting positive staining (Fig. 2B). Higher levels of positive staining, in excess of $80 \%$, were noted in cells treated with 400 and 800 MCM hydrogen peroxide (Fig. 2C and D). 


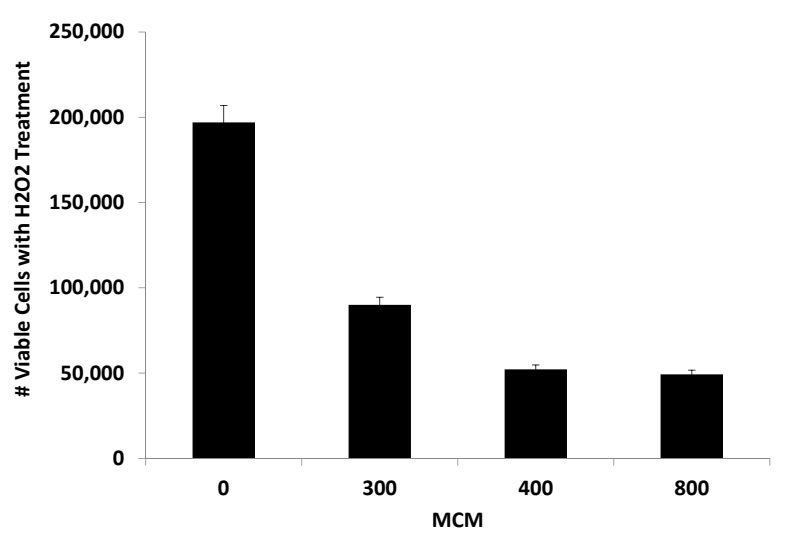

Fig. (1). Decrease in cell viability in response to hydrogen peroxide treatment. Cells treated with (300 MCM, $400 \mathrm{MCM}$ and 800 $\mathrm{MCM}$ ) or without (0 MCM) hydrogen peroxide (for $90 \mathrm{~min}$.) were seeded in $1 \mathrm{ml}$ wells in a 24 well plate at 50,000 cells $/ \mathrm{ml}$ and incubated for 72 hours. Cells were trypsinized and viable cell numbers were recorded using the Trypan Blue Dye Exclusion Method. Data represents results from triplicate observations (mean \pm SEM, $n=3$ ). One-way ANOVA shows a significant treatment effect $(\mathrm{F}=815 ; \mathrm{p} \leq 0.001)$. This experiment was repeated twice with similar results.

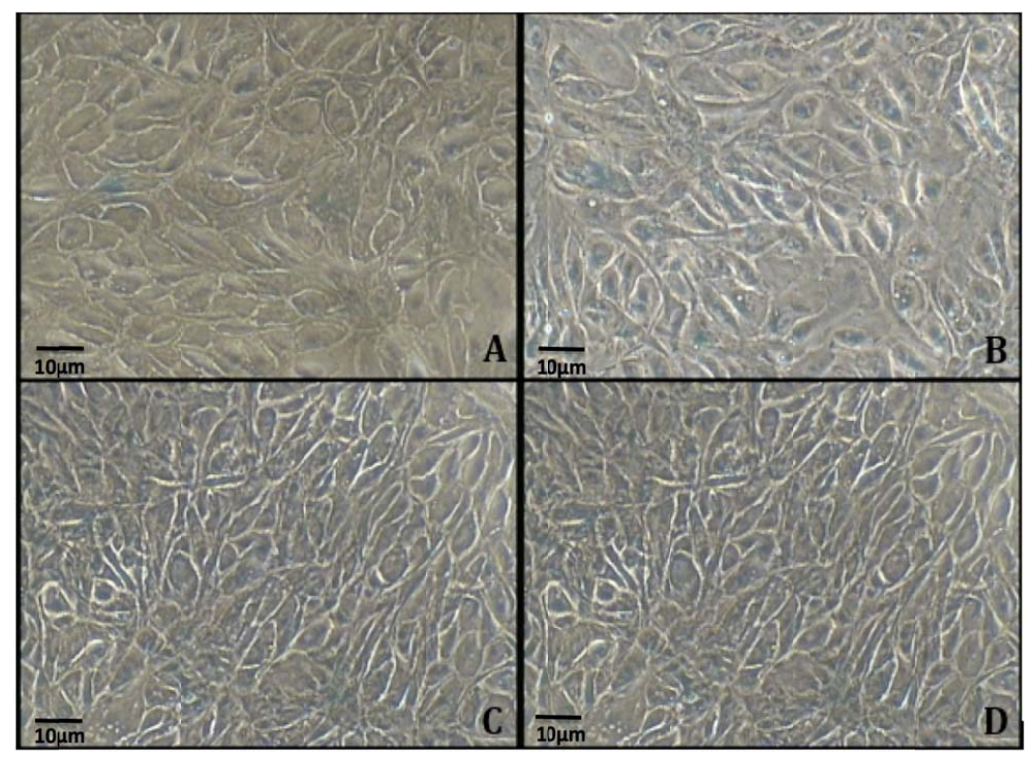

Fig. (2). Photomicrograph of ARPE19 cells without (A) and with (B,C,D) hydrogen peroxide treatment and stained with SABETA-GAL. ARPE-19 cells without hydrogen peroxide treatment (0 MCM) were cultured in conditioned media to full confluence and stained with SA-BETA-GAL for 24 hours, A. Results from cells treated with hydrogen peroxide are shown in B. (300MCM), C. (400 MCM and D. (800 MCM) (200 X magnification).

\subsection{Dose Dependent Increase in Cell Senescence in Response to Oxidative Stress from Hydrogen Peroxide Treatment}

Based on the percent of ARPE19 cells with positive statining of SA-BETA-GAL, Fig. (3) shows an increase in the concentration of hydrogen peroxide in the cell medium led to a corresponding increase in ARPE19 cell senescence. At 0 MCM, a low level of senescence was observed (12\% cells with positive staining). This level was increased to $60 \%$ with hydrogen peroxide treatment at $300 \mathrm{MCM}$. At $400 \mathrm{MCM}$, hydrogen peroxide induced a high level of cell senescence with more than $80 \%$ cells stained positive for SA-BETA-GAL; a marker for cell senescence. 


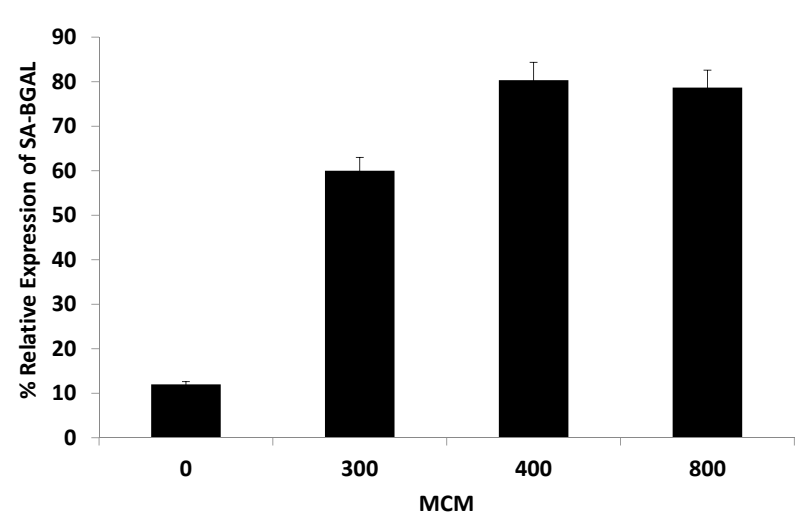

Fig. (3). Increase in ARPE19 cell senescence in response to increased levels of hydrogen peroxide concentration (oxidative stress). Cells with and without hydrogen peroxide treatments were incubated with Beta Galactosidase stain for 24 hours. Blue, positive cells vs non-stained cells were then counted to calculate the percent expression and cell senescence (mean \pm SEM, $n=3$ ). One-way ANOVA shows a significant treatment effect $(\mathrm{F}=614 ; \mathrm{p} \leq 0.001)$. This experiment was repeated twice with similar results.

\section{DISCUSSIONS}

Hydrogen peroxide has a profound effect on cell proliferation in the cultured ARPE19 cells. Untreated cells $(0$ MCM) showed a significant increase in the number of viable cells from 50,000 to 197,000 in a 72 hour incubation period. However, for cells treated with $300 \mathrm{MCM}$ of hydrogen peroxide, the number of viable cells increased only to 89,980 and then to 52,167 when treated with $400 \mathrm{MCM}$. Cells treated with $800 \mathrm{MCM}$, exhibited a slight decrease in cell number from 50,000 to 49,263 . These results strongly suggest that oxidative stress from hydrogen peroxide treatment posts a significant inhibition of ARPE19 cell proliferation.

This is the first study to show that ARPE cells treated with 0, 300, 400 and 800 MCM hydrogen peroxide significantly increase positive staining for Senescence-Associated Beta Galactosidase and significantly decrease cell viability. Cells treated with 0 MCM exhibited a background level of senescence (12\%) which is consistent with previous reports of senescence related changes in this ARPE19 cell line [7]. It is of particular interest to note that cells treated with $300 \mathrm{MCM}$ hydrogen peroxide had a significant increase to nearly $60 \%$ of the cells with positive Beta Galactosidase staining. In cells treated with $400 \mathrm{MCM}$ hydrogen peroxide, more than $80 \%$ of the cells were SA-betaGal positive. Similarly, in cells treated with 800 MCM hydrogen peroxide, about $80 \%$ of cells were positive for Beta Galactosidase, suggesting that $400 \mathrm{MCM}$ is an optimum concentration of hydrogen peroxide to induce significant senescence in cultured ARPE19 cells.

Others have reported oxidative stress on human retinal pigment epithelial cells in culture [8,9]. Arend et al. treated ARPE 19 cells with hydrogen peroxide for 2 hours (400 to $2000 \mathrm{MCM}$ ) and found no change in cell viability at 400 MCM [8]. This is contrary to our results in the present study showing a significant decrease in cell viability at 300,400 and 800 MCM Fig. (1). This may be due to a difference in experimental details (such as length of hydrogen peroxide incubation and passage number of our cell line, which may have increased senescence). In another study, Yu et al. treated primary cultures of human retinal pigment epithelial cells (at low passages P3-P5) with low hydrogen peroxide concentrations (50-150 MCM) [8]. In comparison to our study using a different cell line (ARPE19 with senescentrelated changes), a direct comparison of results between our studies is not readily relevant.

\section{CONCLUSION}

Our study shows that hydrogen peroxide treatment in vitro induces senescence in cultured ARPE 19 cells, likely from oxidative stress. Furthermore, hydrogen peroxide treatment also inhibited cell proliferation. Considering that our study focuses only on acute exposure to hydrogen peroxide, it clearly indicates that oxidative stress could possibly play a role in the pathogenesis of AMD [7,8]. Additional studies such as inhibition of oxidative damage and supplementation with antioxidants will further validate this premise and shed more light on the nature of AMD development $[10,11]$.

\section{LIST OF ABBREVIATIONS}




$\begin{array}{lll}(\text { FBS }) & = & \text { Fetal Bovine Serum } \\ (\text { MCM }) & = & \text { Micromolar } \\ (\text { RPE }) & = & \text { Retinal Pigment Epithelium } \\ (\text { SA-beta-Gal }) & = & \text { Senescence-Associated beta galactosidase }\end{array}$

\section{AUTHOR CONTRIBUTION}

Nona Aryan conceived, designed and performed experiments; Andrew T. Tsin co-designed experiment; Brandi S. Betts-Obregon provided technical support; Nona Aryan, Brandi S. Betts-Obregon, George Perry and Andrew T. Tsin analyzed data, interpreted results, wrote manuscript and provided other related support.

\section{CONFLICT OF INTEREST}

The authors confirm that this article content has no conflict of interest.

\section{ACKNOWLEDGEMENTS}

This research was supported in part by a grant from the National Institute on Minority Health and Health Disparities (G12MD007591) from the National Institutes of Health. We thank Jessica Buikema for technical assistance in the preparation of this manuscript.

\section{REFERENCES}

[1] Green WR, Enger C. Age-related macular degeneration histopathologic studies. The 1992 Lorenz E. Zimmerman Lecture. Ophthalmology 1993; 100(10): 1519-35

[http://dx.doi.org/10.1016/S0161-6420(93)31466-1] [PMID: 7692366]

[2] Bai Y, Ma J-X, Guo J, et al. Müller cell-derived VEGF is a significant contributor to retinal neovascularization. J Pathol 2009; 219(4): 446-54.

[http://dx.doi.org/10.1002/path.2611] [PMID: 19768732]

[3] Lu L, Hackett SF, Mincey A, Lai H, Campochiaro PA. Effects of different types of oxidative stress in RPE cells. J Cell Physiol 2006; 206(1): $119-25$. [http://dx.doi.org/10.1002/jcp.20439] [PMID: 15965958]

[4] Mullins RF, Russell SR, Anderson DH, Hageman GS. Drusen associated with aging and age-related macular degeneration contain proteins common to extracellular deposits associated with atherosclerosis, elastosis, amyloidosis, and dense deposit disease. FASEB J 2000; 14(7): $835-46$.

[PMID: 10783137]

[5] Liang FQ, Godley BF. Oxidative stress-induced mitochondrial DNA damage in human retinal pigment epithelial cells: a possible mechanism for RPE aging and age-related macular degeneration. Exp Eye Res 2003; 76(4): 397-403. [http://dx.doi.org/10.1016/S0014-4835(03)00023-X] [PMID: 12634104]

[6] Beatty S, Koh H, Phil M, Henson D, Boulton M. The role of oxidative stress in the pathogenesis of age-related macular degeneration. Surv Ophthalmol 2000; 45(2): 115-34.

[http://dx.doi.org/10.1016/S0039-6257(00)00140-5] [PMID: 11033038]

[7] Kozlowski MR. The ARPE-19 cell line: mortality status and utility in macular degeneration research. Curr Eye Res 2015; 40(5): 501-9. [http://dx.doi.org/10.3109/02713683.2014.935440] [PMID: 24977298]

[8] Arend N, Wertheimer C, Laubichler P, Wolf A, Kampik A, Kernt M. Idebenone prevents oxidative stress, cell death and senescence of retinal pigment epithelium cells by stabilizing BAX/Bcl-2 ratio. Ophthalmologica 2015; 234(2): 73-82. [http://dx.doi.org/10.1159/000381726] [PMID: 26044821]

[9] Yu AL, Fuchshofer R, Kook D, Kampik A, Bloemendal H, Welge-Lüssen U. Subtoxic oxidative stress induces senescence in retinal pigment epithelial cells via TGF-beta release. Invest Ophthalmol Vis Sci 2009; 50(2): 926-35. [http://dx.doi.org/10.1167/iovs.07-1003] [PMID: 19171648]

[10] Tso MO. Retinal Diseases. Philadelphia: JB Lippincott Co. 1988; pp. 187-214.

[11] Glickman RD. Progress in Brain Research. The Netherlands: Elsevier Science 2001; pp. 699-712.

(C) Aryan et al.; Licensee Bentham Open

This is an open access article licensed under the terms of the Creative Commons Attribution-Non-Commercial 4.0 International Public License (CC BY-NC 4.0) (https://creativecommons.org/licenses/by-nc/4.0/legalcode), which permits unrestricted, non-commercial use, distribution and reproduction in any medium, provided the work is properly cited. 